\title{
DIFFERENT CRITERIA BETWEEN DERIVATIONAL AND INFLECTIONAL MORPHEMES IN ENGLISH
}

\author{
Adi Yusuf \\ Universitas Pesantren Tinggi Darul Ulum \\ e-mail: adiyusuf@fbs.unipdu.ac.id
}

\begin{abstract}
In learning English words, it is very important to know the smallest unit which contributes to determine a new word or meaning, called 'morpheme'. There are two kinds of morphemes whether they create a new word or a new meaning: derivational morphemes and inflectional morphemes. This paper would like to discuss some different criteria that help to distinguish between English inflectional and derivational affixes, they are: (a) derivational affixes change a word and/or the meaning, but not all. However, inflectional affixes do not., (b) the place of derivational affixes is closer than that of inflectional affixes, the place of inflectional affixes is outside derivational affixes., (c) derivational affixes apply to restricted classes of stems, while inflectional affixes barely have exception., (d) derivational affixes are not relevant to the syntax, however inflectional affixes are relevant., (e) derivational morphemes can be attached by prefixes and suffixes, on the other hand, inflectional morphemes are only added by suffixes., and (f) derivational morphemes are semantically opaque, while inflectional morphemes are rarely semantically opaque.
\end{abstract}

Keywords: morphemes, derivational morphemes, inflectional morphemes, opaque

\section{INTRODUCTION}

When learning a language, we definitely learn parts of words. As mentioned in the Oxford Advanced Learner's Dictionary edited by Crowther (1995: 1374), a word is 'a sound or group of sounds that expresses a meaning and forms an independent unit of a language'. Fromkin et al. (2003: 73-74) divide English words into two categories: content words and function words. Content words can be called the open class words because we can and regularly do add new words to these classes. Nouns, adjectives, verbs, and adverbs are the content words.

These content words show us about concepts such as, objects or nouns, action, attributes, and ideas that we can think. Function words also called closed class words, on the contrary, refer to other classes of words that do not have clear lexical meaning or obvious concepts associated with them. Conjunctions such as, and, or, but, etc.; prepositions such as in, on, at, of, etc.; articles the, a/an, and pronouns like she, he, it, etc. are function words. These kinds of words have a grammatical function. For example, the articles indicate whether a noun is definite or indefinite - the boy or a boy. The preposition of indicates possession as in "the book of yours," but this words indicates many other kinds of relations too.

Then, to understand 'a word', especially its parts and meaning, we firstly have to know the smallest unit of it, called morpheme. VanPatten and Benati (2010: 109) define a morpheme is 'the smallest unit of language that carries any kind of meaning. Fromkin et al. (2003: 77-78) divide a morpheme into two kinds: free morphemes and bound morphemes. Some morphemes like mother, sleep, gentle, and man may constitute words by themselves. These are free morphemes. Other morphemes such as -ish, ness, -ty, -ly, dis-, im-, ir, -im-, -un are never words by themselves, but are always parts of 
words. These affixes are bound morphemes'. From the explanation and examples, it can be said that free morphemes can indicate words by themselves, but bound morphemes must be combined with other morphemes to form words. Finally, in the case of morphemes, whether they create a new word or a new meaning or not, they are divided into two kinds: derivational morphemes and inflectional morphemes.

This paper presents some different criteria that may help us to differentiate between English derivational morphemes and inflectional morphemes.

\section{DERIVATIONAL MORPHEMES}

Derivational morphemes refer to bound morphemes added to a root morpheme or stem that produce a new word with a new meaning. Fromkin et al. (2003: 83) explain that bound morphemes such as -ify, -cation, -ity, -ure, ment, etc. are called derivational morphemes since when they are attached to a root morpheme or stem, a new word with a new meaning is derived. The addition of -ify changes an adjective into a verb (e.g. pure - purify) which means 'to make pure' then when it is combined with the suffix -ation (e.g. purify - purification) it will be a noun with the meaning 'the process of making pure'. Similarly, VanPatten and Benati (2010: 110) mention that 'derivational morphology' definitely focuses on how new words are formed from other words. The results of new words always involve either changes in meaning or changes in syntactic function. For example, from the word possible we get the 'derived' a word impossible. This derivation certainly results in a change of meaning: impossible is the opposite of possible. Another deriva- tion of the word possible is possibility. In this matter, there is, of course, a change in syntactic function: possible is an adjective, but possibility is a noun.

Besides, Fromkin et al. (2003: 86) state that derivational morphemes have clear semantic content. In this sense they are just like content words, but that they are not words. When a derivational morpheme is combined with a root or stem, it will add meaning. The derived word may also be of a different grammatical class than the original word, as shown by suffixes such as $-a b l e$ and $-l y$. When a verb is suffixed with-able, the result is an adjective, as in desire + able, adore + able. When the suffix $-e n$ is added to an adjective, a verb is derived, as in light $+e n$. Look at the following Examples of derivational morphemes below:

\begin{tabular}{ll}
\hline Noun & Adjective \\
\hline mother & mother + ish \\
\hline Skill & skill + ful \\
\hline Speech & speech + less \\
\hline Virtu & virtu + ous \\
\hline alcohol & alcohol + ic \\
\hline Verb & Noun \\
\hline free & free + dom \\
\hline paint & paint + ing \\
\hline arrive & Arriv + al \\
\hline predict & predict + ion \\
Sing & Sing + er \\
\hline & \\
\hline Adjective & Adverb \\
\hline happy & Happi + ly \\
\hline successful & successful + ly \\
\hline free & free + ly \\
\hline quick & quick + ly \\
\hline exact & exact + ly \\
\hline
\end{tabular}




\begin{tabular}{ll}
\hline Noun & Verb \\
\hline summary & Summar + ize \\
\hline beauty & Beaut + ify \\
\hline Vaccin & Vaccin + ate \\
\hline Haste & Haste $+\mathrm{n}$ \\
\hline Adjective & Noun \\
\hline tall & tall + ness \\
\hline honest & honest + y \\
\hline feudal & feudal + ism \\
\hline specific & specific + ity \\
\hline & \\
\hline Verb & Adjective \\
\hline read & read + able \\
\hline educate & educat + ional \\
\hline creat & creat + ive \\
\hline run & run + (n)y \\
\hline & \\
\hline Noun & Adjective \\
\hline quarter & quarter + ly \\
\hline grace & grace + ful \\
\hline speech & speech + less \\
\hline thirst & thirst $+\mathrm{y}$ \\
\hline advantage & advantage + ous \\
\hline Adjective & \\
\hline short + en & short + en \\
\hline modern & modern + ize \\
\hline different & te \\
\hline equal & sifferent + iate \\
\hline
\end{tabular}

Not all derivational morphemes cause a change in grammatical class.

\begin{tabular}{ll}
\hline Noun & Noun \\
\hline friend & friend + ship \\
\hline Child & child + hood \\
\hline
\end{tabular}

\begin{tabular}{ll}
\hline garden & garden + er \\
\hline human & human + ity \\
\hline Verb & Verb \\
\hline Do & un + do \\
\hline Flow & over + flow \\
\hline Close & en + close \\
\hline Cover & re + cover \\
\hline & \\
\hline Adjective & Adjective \\
\hline Pink & pink + ish \\
\hline Possible & im + possible \\
\hline Regular & ir + regular \\
\hline Flammable & in + flammable \\
\hline
\end{tabular}

Many prefixes fall into this category:

\begin{tabular}{ll}
\hline Prefix & Word \\
\hline a & a + moral (adj.) \\
\hline mid & mid + night (noun) \\
\hline auto & auto + biography (noun) \\
\hline hyper & hyper + active (adj.) \\
\hline Dis & dis + agree (verb) \\
\hline mono & mono + theism (noun) \\
\hline post & post + war (adj.) \\
\hline re & re + print (verb) \\
\hline mal & mal + practice (noun) \\
\hline semi & semi + annual (adj.) \\
\hline
\end{tabular}

There are also suffixes of this type:

\begin{tabular}{ll}
\hline Word & Suffix \\
\hline Vicar + age (noun) & age \\
\hline yellow + ish (adj.) & ish \\
\hline America + n (noun) & $\mathrm{n}$ \\
\hline fadd + ist (noun) & ist \\
\hline music + ian (noun) & ian \\
\hline pun + ster (noun) & ster \\
\hline
\end{tabular}




\section{INFLECTIONAL MORPHEMES}

Many languages, including English, have bound morphemes too that have a strictly grammatical function. The bound morphemes may indicate tense, number, gender, case, and so on. Such bound morphemes are called inflectional morphemes' (Fromkin et al., 2003: 100). VanPatten and Benati (2010: 110) state that 'inflectional morphology refers to adding elements to a word that do not change the word's function or meaning, but might serve as a grammatical device to things like person, number, tense, plurality, and so on. Thus, plural $-s$ or $-e s$ in English is an inflection attached to countable nouns to indicate that the number of the nouns is more than one (e.g. cat - cats, car-cars) and the suffix $-e d$ is an English inflection added to verbs that indicates past tense (cook - cooked, watch - watched).

Akmajian, et al. (2001: 43) explain that in English, all inflectional affixes are suffixes, unlike derivational affixes which include both suffixes and prefixes. Here are the lists of inflectional affixes in English:

\section{A. Noun inflectional suffixes}

1. Plural marker - s or - es

The inflectional suffix $-s$ or $-e s$ added to countable nouns is used to express plurality (e.g. book - books, bus - buses/ busses) in sentences (e.g. the books are here, there are six buses). In this matter, when to use the appropriate inflectional suffix i.e. the correct choice of the suffix $-s$ or $-e s$ is prescribed by grammar, it is related to syntax.

\section{Possessive marker's}

The suffix $-s$ can also be used to express possessiveness when it is preceded by an apostrophe ('). For instance, the expression Mary's dictionary, clearly shows that the dictionary belongs to Mary.

\section{B. Verb inflectional suffixes}

1. Third person present singular marker $-\mathrm{s}$

The other use of the inflectional suffix $-s$ is to mark that the subject of sentences in present tense is singular. For example, He drives the car carefully, the verb drive is added by the suffix $-s$ in simple present obviously indicate that the subject is singular.

\section{Past tense marker - ed}

To indicate that an activity happens in the past, English frequently uses the suffix -ed. For instance, I visited my grandmother last week, the suffix -ed here is added to the verb visit in order that readers or listeners understand that the action occurs in the past.

\section{Progressive marker - ing}

The - ing form added to a base word can indicate progressive. In the sentence, He is praying in the mosque, it can be clearly seen that the base word pray is combined with the suffix -ing to mark that the activity is taking place/in progress at the moment of speaking.

\section{Past participle markers - en or -ed}

Inflectional suffixes $-e n$ or $-e d$ can be used to show an activity which has already been done or has never been done. For example, $\mathrm{He}$ has eaten the apple or I have answered all the questions, in this case, the inflectional suffix $e n$ and $-e d$ is used in present perfect.

\section{Adjective inflectional suffixes}

1. Comparative marker - er

One way to describe that one thing or a person has more quality than that of being 
compared is by using the inflectional suffix -er. This suffix need to be combined with an adjective (e.g. My house is bigger than yours).

\section{Superlative marker - est}

The suffix - est added to a base word i.e. an adjective, it will mark that one thing or a person has highest quality among others. For example, $\mathrm{He}$ is the tallest student in this class. This indicates that the pronoun be has the highest quality i.e. in the matter of height compared to the other students in the class.

\section{DIFFERENT CRITERIA BETWEEN THE ENGLISH DERIVATION AND INFLECTION}

O'Grady et al. (1989: 108-109) mention three criteria that help to distinguish between inflectional and derivational affixes in English, they are:

The first criterion, inflection does not change the grammatical category of the word to which it applies. This follows from the fact that inflection simply marks subclasses of already existing words; it does not create new words, like books and worked. In contrast, derivational affixes characteristically change the category and/ or the meaning of the form to which they apply and are therefore said to create a new word. For example, the suffix -ize changes the category of an adjective modern with the meaning most recent into a verb modernize with the meaning to make something modern.

The second criterion, inflectional affixes have to do with their positioning within the word. A derivational affix must be closer to the root than an inflectional affix. For instance, the word brotherhoods, brother is a root and hood is a derivational affix, then the addition $-s$ is an inflectional affix. The positioning of inflectional affixes outside derivational affixes obviously reflects the fact that inflection takes place after all word formation processes, including derivation.

The third criterion which help us to differentiate between inflectional and derivational affixes is on the productivity, the relative freedom with which they combine with roots or stems of the appropriate category. Inflectional affixes typically have very few exceptions. For instance, The suffix $-s$ can combine with mostly nouns, categorized as countable nouns, that indicates a plural form (a few exceptions such as children, oxen, mice, deer, feet, etc. categorized as irregular plural nouns). On the contrary, derivational affixes cannot combine with all categories, they can be added to restricted classes of roots or stems. The phenomenon of changing classes of roots into adjectives such as peace - peaceful, skill - skillfull skilful, beauty - beautiful, help - helpful, care - careful, fruit - fruitful, etc. Here, the derivational suffix -ful can be applied to the roots and it changes them into adjectives. However, the addition of the suffix - ful cannot be applied to all roots to form adjectives, like satisfy, confuse, interest. In this case, to make them adjectives we need to add the suffix - ed or -ing.

In addition, Plag (2002: 19-21) proposes the following criteria:

The first, Inflectional suffixes are relevant for the syntax. This means that there is relevance for the building of sentences and are referred to rules prescribed by the grammar. For examples, She cooks rice or The pictures are/"is wonderful, there is a grammatical rule in English that prescribes agreement between the subject and the verb i.e. when the subject is singular, the verb must also agree with the subject or indicate singular as exemplified in the former example that the suffix $-s$ needs to be added to the root cook above and the deter- 
mination of filling a verb whether singular or plural as in the latter example. This rule is called subject-verb agreement, which is also related to plural marking in sentences. Derivational affixes, however, are not relevant for the syntax. For example, whether the noun ends in - er, - ee, -ian, -ist, -ant, etc. or whether the noun is morphologically complex at all, is not relevant for building sentences.

The second, Inflectional morphemes are always expressed by suffixes like works, picked, children, etc. Some of them are marked irregularly by non-affixational means, like man-men, deer-deer, goose-geese, foot-feet, child-children, etc. There is no inflectional prefix in English. On the contrary, derivational morphemes can be formed by the addition of prefixes and or suffixes, such as accurate - inaccurate, curious curiosity, happy - happiness, etc. Another example, the word untruthfulness, shows that there are a prefix and suffixes. In addition, derivational suffixes can and do occur inside other derivational suffixes.

The next criterion, inflectional suffixes do not change the category of the base word (root). The suffix - s added to countable nouns mark the plurality without changing the category of the root as in worker - workers, trainee - trainees. Besides, the suffix -ed combined with regular verbs shows past tense (e.g. visit visited, listen - listened) will not change the category. In contrast, derivational affixes mostly change the category of the base word. For examples, the suffix -less makes a noun become an adjective (e.g. speechless), the suffix -ness changes an adjective into a noun (e.g. happiness), and the prefix -en turns an adjective to a verb (e.g. enrich). However, not all derivational affixes are category-changing, as exemplified by most prefixes (as e.g. in pre-war, decolonialize, non-issue), or by the suffix -ism, which can attach to nouns to form nouns (e.g. Terrorism). This criterion is like that of proposed by O'Grady et al. (1989: 108-109) in the first criterion above, here there is an additional explanation of the category-changing of derivational affixes; not all derivational affixes change the category of the base word.

The last criterion, infrequently, inflectional morphemes are semantically opaque - the meaning of the words added by suffixes can be easily inferred from their base words. For instances, He arrived here five days ago or My mother buys vegetables, in these sentences we can understand the meaning of the words combined with the inflectional suffix $-e d$ as in the first sentence and the inflectional suffix $-s$ as in the second sentence. Derivational morphemes, on the other hand, are often semantically opaque. For example, the meaning of unearth and the meaning of the ingredient morphemes $u n$ - and earth, can be observed that the meaning of unearth is not the sum of the meaning of its parts. The meaning of $u n$ - can be paraphrased as 'not' and the word earth with the meaning 'name of a planet', whereas the meaning of unearth is 'to dig up'. Thus the meaning of the derived word cannot be inferred from the basis of its constituent morphemes, it is to some extent can be said opaque, or non-transparent.

Look at the following examples of English words with an opaque meaning below:

\begin{tabular}{ll}
\hline Words & Meaning \\
\hline $\begin{array}{l}\text { sound }+ \text { ly }= \\
\text { soundly }\end{array}$ & $\begin{array}{l}\text { to show a manner of how one } \\
\text { sleeps deeply }\end{array}$ \\
\hline hard + ly = hardly & almost not \\
\hline re + sign = resign & $\begin{array}{l}\text { to give up a job by giving infor- } \\
\text { mation to the employer that you } \\
\text { are leaving }\end{array}$ \\
\hline re + tail = retail & $\begin{array}{l}\text { (verb) to sell goods to the public, } \\
\text { for example, in shops. (noun) the } \\
\text { activity of selling goods to the } \\
\text { public with small quantities }\end{array}$ \\
\hline
\end{tabular}


The examples in the table above clearly shows us that the meaning of the derived words is hard to understand. The derivational suffix $l y$ is usually used to tell how something is done and the meaning added by the suffix is easily understood. For instance, the suffix -ly combined with the adjective careful, the meaning is 'with great attention or in a careful manner'. However, this suffixation does not always show a manner of how something is done. The derived words as shown in the first and second line in the table above, for example, the meaning cannot be observed from their parts. The meaning of the word sound 'something can be heard' is different from that of the result of the combination i.e. added by the suffix $-l y$ as in soundly with the meaning 'to tell of how one sleeps soundly. This also occurs in the derived word in the second line. The base word hard has the same meaning as 'difficult', when it is added by the suffix $-l y$, it does not show how something is done i.e. 'with difficult manner', instead of 'almost not'.

In addition, the derivational prefix $r e$ - is usually used to indicate repetition 'again', for example, the meaning of rewrite and the meaning of its parts re- and write, can be observed that the meaning of rewrite is the sum of the meaning of its parts i.e. 'to write again'. Yet, we cannot generalize that the prefix re-always has the meaning 'again' as exemplified in the fourth and the fifth line in the table above. The prefix re-added to the base word sign becomes resign, for instance in a sentence, they want to resign from the company because they want to work in another company that is more bona fide. In this case, the meaning of the derived word resign is 'to give up a job by giving information to the employer that one is leaving' instead of 'to sign again'. The next phenomenon related to the opaque meaning of derivation can be seen in the word retail as presented in the last line in the above table. The base word tail when it is a noun category means 'a part of an animal's body' and when it is a verb category means 'to follow and watch someone in a close distance to get information secretly'. However, the derived word retail means 'the activity of selling goods to the public with small quantities' when it is a noun category, and 'to sell goods to the public' when it is a verb category.

\section{CONCLUSION}

Based on the explanation above, It can be concluded that derivational morphemes are bound morphemes added to a root morpheme or stem to form a new word with a new meaning. In contrast, inflectional morphemes are bound morphemes added to a word that do not change the word's function or meaning, but might serve as a grammatical category to things like person, number, tense, plurality, and so on.

There are some criteria that distinguish between derivational and inflectional morphemes. The first, derivational affixes mostly change the category and/or the meaning of the form to which they apply. In contrast, inflectional affixes do not change the grammatical category of the base words to which they combine and they do not form new words. The second, derivational morphemes can occur inside derivation and the position of derivational morphemes is closer to the root than that of inflectional morphemes', but inflectional morphemes may occur after or outside derivation. The third, derivation is often restricted in its productivity; certain derivational morpheme can combine with only certain words in categorychanging. Inflection, however, is fully productive i.e. certain inflectional suffixes can combine with words with the same category. The 
forth, derivation is not syntactically relevant; it is not relevant for building sentences. On the contrary, inflection is syntactically relevant. The fifth, derivation is not restricted to suffixation. Inflection, on the contrary, is always suffixional and there is no inflectional prefix in English. The last, derivation is often semantically opaque. Inflection, on the other hand, is rarely semantically opaque - the meaning of the words attached by suffixes can be inferred from their roots.

\section{REFERENCES}

Akmajian, A., Demers, R.A., Farmer, A.K., and Harnish, R.M. 2001. Linguistics. An In- troduction to Language and Communication. London: The MIT Press.

Crowther, J. editor. 1995. Oxford Advanced Learner's Dictionary. New York: Oxford University Press.

Fromkin, V., Rodman, R., and Hyams, N. 2003. An Introduction to Language. Massachusetts: Thomson Wadsworth.

O'Grady, W., Dobrovolsky, M., and Aronoff, M. 1989. Contemporary Linguistics. New York: St. Martin's Press.

Plag, I. 2002. Word-Formation in English. Universitet Siegen: Cambridge University Press.

VanPatten, B. and Benati, A.G. 2010. Key Terms in Second Language Acquisition. New York: Continuum. 